\title{
Pemberian teknik Door in the Face dan Foot in the Door untuk meningkatkan perilaku prososial
}

\author{
Luly Luliyarti ${ }^{*}$, Widyastuti ${ }^{1}$, Kurniati Zainuddin ${ }^{1}$, \& Nurul Fajriah Yahya ${ }^{2}$ \\ ${ }^{1}$ Fakultas Psikologi, Universitas Negeri Makassar, Makassar \\ ${ }^{2}$ Fakultas Psikologi, Universitas Persada Indonesia Y.A.I, Jakarta
}

\begin{abstract}
Abstrak
Penelitian ini bertujuan untuk mengetahui efektivitas teknik door in the face dan foot in the door dalam meningkatkan perilaku prososial serta mengetahui perbedaan efektivitas pemberian teknik kesepakatan dalam meningkatkan perilaku prososial. Partisipan penelitian ini melibatkan 161 siswa SMA X (Kota) dan SMA Y (Desa) berusia 16-19 tahun. Penelitian ini menggunakan metode eksperimen dengan desain multiple treatments and controls with pretest. Hasil penelitian menunjukkan, pertama, ada perbedaan efektivitas pemberian teknik door in the face dan foot in the door dalam membentuk kesepakatan terhadap perilaku prososial. Teknik foot in the door lebih efektif dalam membentuk kesepakatan terhadap perilaku prososial dibandingkan teknik door in the face. Kedua, ada perbedaan efektivitas pemberian teknik kesepakatan (door in the face dan foot in the door) dalam meningkatkan perilaku prososial di SMA X dan SMA Y. Pemberian teknik door in the face dan foot in the door lebih efektif dalam meningkatkan perilaku prososial di SMA Y dibandingkan SMA X. Penelitian ini dapat dijadikan bahan kajian untuk mengetahui penyebab dibalik perbedaan perilaku prososial yang ditampilkan meskipun mendapatkan perlakuan yang sama.
\end{abstract}

Kata kunci: perilaku prososial, door in the face, foot in the door

\begin{abstract}
This study aims to determine the effectiveness of the technique of door in the face and foot in the door in improving prosocial behavior and find out the difference in the effectiveness of giving agreement techniques in improving prosocial behavior. The participants of this study involved 161 students from SMA X (City) and SMA Y (Village) aged 16-19 years. This study uses an experimental method with the design of multiple treatments and controls with the pretest. The results showed, first, there were differences in the effectiveness of providing door in the face and foot in the door techniques in forming agreements on prosocial behavior. The foot in the door technique is more effective in forming agreements on prosocial behavior than the door in the face technique. Secondly, there were differences in the effectiveness of providing agreement techniques (door in the face and foot in the door) in improving prosocial behavior in SMA X and SMA Y. The provision of the door in the face and foot in the door techniques is more effective in improving prosocial behavior in SMA Y compared to SMA X. This research can be used as study material to find out the causes behind the different prosocial behavior displayed despite getting the same treatment.
\end{abstract}

Keywords: behavior, door in the face, foot in the door

\section{Pendahuluan}

Manusia adalah makhluk sosial yang memiliki kemampuan secara psikologis untuk menyatu dengan individu lain. Individu dituntut untuk saling memberi pertolongan, saling memahami, dan hidup berdampingan karena tidak ada individu yang dapat hidup sendiri. Oleh karena itu,

Naskah masuk:16 April 2019

Naskah diterima: 18 Februari 2020 perilaku menolong atau prososial teramat penting (Nashori, 2008). Sayangnya, individu tidak melakukan perilaku prososial dalam segala kondisi (Barr \& Higgins-D’Alessandro, 2007). Hal tersebut dipengaruhi oleh pengambilan keputusan pada individu untuk memberi pertolongan atau tidak memberi pertolongan (Barr \& HigginsD’Alessandro, 2007). Shadiqi (2018) mendefini-

*Fakultas Psikologi, Universitas Negeri Makassar Jl. Mapala No.1, Makassar, Sulawesi Selatan, Indonesia, 90222 E-mail: lulyluliarti1991@gmail.com 
sikan perilaku menolong atau yang biasa disebut perilaku prososial sebagai segala bentuk tindakan sukarela dalam menolong orang lain sehingga memberi manfaat positif secara langsung kepada orang yang ditolong dan mungkin tidak memberi manfaat secara langsung kepada si penolong. Shadiqi (2018) menjelaskan bahwa terdapat berbagai faktor yang dapat memengaruhi perilaku seseorang dalam memberikan pertolongan, yaitu faktor yang bersifat internal seperti kondisi biologis/genetik, kepribadian, kelekat-an, dan hubungan. Ada juga yang bersifat dyadic seperti faktor situasional, motivasi egosentris, altruisme, kolektivisme, prinsipalisme, maupun respon dari orang yang ditolong. Terdapat pula faktor yang bersifat makro, seperti adanya proses kerja sama dalam kelompok. Dari semua faktor-faktor yang mempengaruhi perilaku prososial, Tusing dan Dillard (2000) menyatakan bahwa kesepakatan lebih mudah diraih dalam bentuk dyadic yang melibatkan persepsi, keyakinan, dan perasaan dalam interaksi sosial. Sehingga, upaya mendapatkan kesepakatan dalam bentuk dyadic dengan memberikan penawaran-penawaran tertentu sebelum akhirnya mengajukan penawaran yang memang diinginkan oleh subyek merupakan cara yang bisa dilakukan dalam intervensi perilaku prososial. Ini merupakan prinsip kerja foot in the door (FITD) dan door in the face (DITF).

Sebetulnya, ada banyak teknik intervensi yang dapat meningkatkan perilaku prososial. Di antaranya adalah school-based intervention yang dinamakan promoting prosocial and emotional skills (CEPIDEA) (Caprara, dkk, 2014), autonomy supportive intervention program (ASIP) (Cheon, Reeve, \& Ntoumanis, 2018), friendship program (Costin \& Jones, 1992), dan mindfulnessbased kindness curriculum (Flook, Goldberg, Pinger, \& Davidson, 2015). Akan tetapi, kondisi dyadic lebih banyak ditekankan dalam teknik DITF dan FITD (Baron \& Byrne, 2005), di mana penolong dihadapkan pada berbagai tawaran sehingga ia bisa mengeksekusi kontrol atau kebebasan kehendak. Sesuai dengan Tusing dan Dillard (2000), cara ini lebih mudah menstimulasi persetujuan dari penolong.

CEPIDEA merupakan program intervensi yang dirancang untuk meningkatkan perilaku prososial dengan cara menurunkan perilaku agresif siswa (Caprara, dkk, 2014). ASIP merupakan program intervensi yang dirancang untuk meningkatkan perilaku prososial siswa dengan mengurangi perilaku antisosial (Cheon, Reeve, \& Ntoumanis, 2018). Friendship program merupakan intervensi yang menjadikan persahabatan sebagai fasilitator dalam responsif emosional sehingga dapat meningkatkan perilaku prososial pada individu (Costin \& Jones, 1992). Mindfulness-based kindness curriculum berupa latihan yang bertujuan untuk menumbuhkan perhatian dan regulasi emosi, dengan penekanan pada praktik kebaikan, seperti empati, terima kasih dan berbagi melalui latihan selama 20-30 menit per minggu selama 12 minggu (Flook, Goldberg, Pinger, \& Davidson, 2015). Nampak bahwa pilihan bebas dan rasional dari si penolong lebih ditekankan oleh DITF dan FITD dibandingkan teknik-teknik lainnya. Walau teknik lowball (Gueguen, Pascual, \& Dagot, 2002) juga mengusahakan adanya kondisi dyadic, pilihan yang ditawarkan DITF dan FITD berbeda dalam prinsip.

Teknik DITF merupakan teknik untuk mendapatkan kesepatan dengan mengajukan penawaran yang besar, ketika ditolak maka diajukan penawaran yang lebih kecil (yang memang diinginkan) (Cann, Sherman, \& Elkes, 1975). Pengertian ini sejalan dengan yang dikemukakan oleh Baron \& Byrne (2005), di mana teknik DITF merupakan teknik untuk mendapatkan kesepakatan dengan memulai permintaan yang besar dan setelah ditolak, mundur ke permintaan yang lebih kecil (permintaan yang memang diinginkan sejak awal). Sedangkan teknik FITD merupakan teknik untuk mendapatkan kesepakatan dengan membuat individu menyepakati penawaran kecil, lalu meningkatkan penawaran yang lebih besar (yang memang diinginkan) (Cann, Sherman, \& Elkes, 1975). DITF merupakan intervensi yang biasa digunakan untuk mempengaruhi individu dalam mengambil keputusan untuk membeli barang, menyumbangkan uang, berderma, atau halhal yang terkait dengan keputusan untuk memberi pertolongan (Mowen \& Cialdini, 1980).

Teknik DITF terbukti efektif dalam mempengaruhi individu dalam mengambil keputusan untuk memberi pertolongan. O'keefe dan Figge (1997) dalam penelitiannya menunjukkan bahwa pada saat permintaan diajukan dengan cara biasa dengan langsung mengajukan permintaan, hanya $17 \%$ individu yang setuju untuk memberi bantuan yaitu berupa persetujuan untuk menjadi pendamping. Namun, dalam kondisi DITF, 50\% individu setuju untuk memberi bantuan. Pada kondisi DITF, diajukan permintaan pertama bahwa individu diminta untuk menjadi pendamping sukarelawan selama dua jam seminggu dalam waktu dua tahun. Hal tersebut ditolak oleh para partisipan dan diajukanlah permintaan kedua yang memang menjadi target permintaan, dan hasilnya menunjukkan bahwa $50 \%$ individu menyatakan kesediaan menjadi pendamping sukarelawan selama dua jam seminggu.

Sedangkan teknik FITD adalah teknik untuk mendapatkan kesepakatan dengan memulai permintaan yang kecil dan setelah disetujui, meningkat ke permintaan yang lebih besar (permintaan yang memang diinginkan sejak awal) (Baron \& Byrne, 2005). FITD merupakan inter- 
vensi yang biasa digunakan untuk memanipulasi kepatuhan, persepsi, kesesuaian, konsistensi, atribusi, dan komitmen untuk mengambil keputusan maupun komitmen dalam memberi pertolongan (Burger, 1999). Teknik FITD terbukti efektif dalam mempengaruhi individu dalam mengambil keputusan untuk memberi pertolongan. Pliner, Hart, Kohl, dan Saari (1974) dalam penelitiannya menunjukkan bahwa individu yang menerima permintaan sebelumnya, secara signifikan individu akan memenuhi permintaan yang lebih besar dibandingkan inidividu yang tidak dikenakan teknik FITD dalam mengajukan permintaan. Dalam kondisi FITD ringan, individu diminta untuk mengenakan pin dalam penggalangan dana keesokan harinya dan setelah individu setuju untuk mengenakan pin, keesokan harinya diajukan permintaan sumbangan. Hasilnya, sebesar 74,1\% individu sepakat untuk memberi sumbangan. Dalam kondisi FITD moderat, individu diminta untuk mengenakan pin dalam penggalangan dana keesokan harinya dan mengajak seluruh keluarga untuk mengenakan pin dalam penggalangan dana dan setelah individu setuju untuk mengajak keluarga, keesokan harinya diajukan permintaan sumbangan. Hasilnya, sebesar 80,8\% individu sepakat untuk memberi sumbangan. Sementara individu yang tidak dikenakan kondisi FITD, hanya $45,7 \%$ individu yang sepakat memberi sumbangan dalam kegiatan penggalangan dana.

Cialdini dkk. (1975) menunjukkan bahwa teknik DITF sebagai bentuk timbal balik, yaitu tanggapan negatif yang tajam pada permintaan pertama menciptakan rasa bersalah kemudian permintaan kedua menawarkan pernyataan yang jelas dan masuk akal. Titik referensi (framing) mungkin menjelaskan fenomena tersebut sebagai tawaran awal yang buruk, menetapkan titik referensi darimana tawaran kedua tampak seperti perbaikan. Selain itu, jika permintaan pertama yang diberikan terlalu besar, akan terlihat sebagai suatu yang tidak rasional, maka individu cenderung menolak permintaan kedua sehingga teknik DITF tidak akan efektif. Sedangkan pada teknik FITD, Freedman dan Fraser (Cialdini, 2007) mencoba menjelaskan bahwa yang mungkin terjadi adalah perubahan perasaan tentang keterlibatan atau tindakan yang diambil. Sekali saja individu menyetujui permintaan yang diberikan maka perilaku indvidu tersebut tidak akan berubah karena individu memandang bahwa dirinya telah melakukan sesuatu yang sesuai kepercayaan dan patuh dengan sebab yang baik. Persetujuan atas tawaran bukan hanya meningkatkan kepatuhan terhadap permintaan serupa yang lebih besar tetapi juga membuat individu ingin melakukan hal dengan jasa lebih besar karena secara tidak langsung berkaitan dengan jasa kecil yang telah individu lakukan sebelumnya.
Berdasarkan efektivitas teknik intervensi DITF dan FITD yang telah dikemukakan, hal tersebut dapat menjadi solusi untuk meningkatkan perilaku pelajar SMA dalam memberi pertolongan, di mana dalam kondisi kritis individu membutuhkan pertolongan namun tidak ada satupun individu yang memberi pertolongan. Faktor lingkungan bisa dikaitkan dengan kehidupan sosial indivdu yang dipengaruhi oleh bentuk komunitas di mana ia hidup. Sudah lazim individu membagi dua komunitas desa dan kota. Kondisi fisik dan sosial di desa dan kota berbeda. Budaya gotong royong masih terasa kental terjadi di pedesaan, sementara di kota individu menganut budaya individualis sehingga cukup banyak berpengaruh pada keputusan individu dalam memberi pertolongan, terutama pelajar SMA (Faridah, 2011). Hasil penelitian yang dilakukan De Grave (2017) menunjukkan bahwa pelajar SMA di Desa, lebih terlibat dalam kegiatan-kegiatan sosial di sekolah dibanding pelajar SMA di Kota.

Adanya perbedaan kondisi antara sekolah di Desa dan di Kota, turut menyebabkan perbedaan perilaku menolong yang ada. Pelajar yang ada di Desa cenderung lebih menganut budaya kolektif dibanding pelajar yang ada di Kota yang cenderung individualis (De Grave, 2017). Oleh karena itu, penelitian ini bertujuan untuk membuktikan pengaruh teknik DITF dan FITD terhadap pembentukan perilaku prososial. Kedua teknik tersebut merupakan teknik untuk merekayasa kepatuhan.

\section{Intervensi Perilaku Prososial: DITF dan FITD}

Cialdini dan Goldstein (Eastwick \& Gardner, 2008) mengemukakan bahwa teknik DITF disebut sebagai teknik kepatuhan dengan permintaan berurutan. Efektivitas DITF lebih dijelaskan sebagai ilustrasi dari norma timbal balik. Individu lebih cenderung untuk menerima permintaan kedua karena melihat bahwa pemohon telah membuat kesepakatan, asalkan pernyataan yang dibuat pemohon masuk akal, maka individu akan lebih mungkin membuat kesepakatan sendiri dengan pindah ke posisi kepatuhan. Individu yang menjadi target akan setuju untuk menerima penawaran, karena merasa beberapa ukuran kewajiban untuk membantu pemohon.

Penelitian pertama tentang teknik DITF dilakukan oleh Cialdini, Vincent, Lewis, Catalan, Wheeler, dan Darby (1975) terhadap sejumlah mahasiswa dengan memberikan sebuah pernyataan untuk menanyakan kesediaan mahasiswa tersebut untuk menjadi pengawas satu kelompok anak-anak di kebun binatang selama beberapa jam tanpa bayaran. Hasil yang diperoleh adalah 83\% mahasiswa yang diajak adalah menolak. Hal 
yang berbeda terjadi pada di situasi lain, di mana mahasiwa diberi pernyataan awal untuk menjadi konselor selama dua jam seminggu, se-lama minimal dua tahun. Hasil penelitian menunjukkan bahwa mahasiswa yang bersedia untuk menemani anak-anak ke kebun binatang meningkat menjadi tiga kali lipat.

Sangat sering dalam interaksi sosial, peserta mulai dengan persyaratan dan tuntutan yang dapat diterima satu sama lain. Agar interaksi untuk melanjutkan ke pernyataan tujuan tercapai dan maka kompromi harus dicapai. Bukti hubungan timbal balik yang terjadi merupakan konsesi dalam masyarakat yang dapat dilihat dalam berbagai istilah dan ungkapanungkapan bahasa "memberi dan menerima". Teknik DITF memberikan penawaran kepada individu untuk melakukan perilaku prososial, ketika individu tidak merasakan akan kerugian tetapi merasa diuntungkan oleh pernyataan yang lebih ringan dari pernyataan awal. Millar (2002) menjelaskan lebih lanjut bahwa penelitian yang memberikan pernyataan bersifat prososial mungkin memberikan penekanan pada peran rasa bersalah. Individu yang menolak pernyataan yang bersifat prososial akan menghasilkan rasa bersalah yang lebih tinggi, sehingga mengarahkan individu untuk menyetujui pernyataan kedua dalam mengurangi rasa bersalah.

Teknik FITD merupakan teknik kepatuhan dengan permintaan berurutan. Hal tersebut sama dengan teknik DITF, tetapi urutan permintaan yang berlawanan. Baron dan Byrne (2005) mengemukakan bahwa FITD merupakan suatu prosedur yang dilakukan untuk memperoleh kesepakatan dengan memberikan permintaan yang lebih kecil dan ketika permintaan tersebut dipenuhi, maka pemohon akan mengajukan permintaan selanjutnya yang lebih besar (yang merupakan permintaan tujuan yang diinginkan sejak awal).

Baron dan Byrne (2005) mengemukakan bahwa berbagai hasil studi terhadap teknik FITD terbukti dalam meningkatkan kesepakatan. Hal tersebut karena teknik FITD bekerja atas dasar prinsip konsistensi. Individu yang telah menyatakan setuju pada permintaan yang lebih kecil di awal akan memberikan persetujuan terhadap pernyatan kedua yang lebih besar karena individu berusaha bersikap konsisten terhadap pernyataan sebelumnya. Selain itu, FITD berpotensi lebih efektif karena manusia secara natural menyukai konsistensi (Festinger, 1962).

Berdasarkan pemaparan yang telah dijelaskan di atas, maka peneliti tertarik untuk melakukan penelitian lebih lanjut mengenai pengaruh teknik DITF dan FITD terhadap perilaku prososial dan juga sebagai upaya dalam menambah literatur ilmiah terkait teknik DITF dan FITD yang sangat minim. Penelitian ini memiliki hipotesis: 1) terdapat perbedaan efektivitas pemberian teknik DITF dan FITD dalam meningkatkan perilaku prososial, di mana FITD diasumsikan akan lebih efektif; 2) terdapat perbedaan efektivitas pemberian teknik DITF dan FITD dalam meningkatkan perilaku prososial di SMA X (Kota) dan SMA Y (Desa).

\section{Metode Penelitian}

\section{Partisipan, Desain, dan Prosedur}

Partisipan dalam penelitian ini berjumlah 161 siswa, yaitu 76 siswa di SMA X dan 85 siswa di SMA Y yang berusia 16-19 tahun dan merupakan siswa yang masih aktif di sekolah. Partisipan tersebut diperoleh dengan teknik cluster sample dengan alasan bahwa teknik penarikan sampel dengan melakukan randomisasi terhadap kelompok tergolong efisien dari segi waktu dan biaya dibanding dengan cara random sederhana. Partisipan dibagi ke dalam dua kelompok yaitu kelompok eksperimen (KE) dan kelompok kontrol (KK). Cluster sample adalah teknik penarikan sampel dengan melakukan randomisasi terhadap kelompok, bukan terhadap subjek secara individual (Goodwin, 2010).

KE merupakan kelompok yang akan diberikan perlakuan dengan memberi teknik DITF dan FITD. KK merupakan kelompok yang tidak diberi perlakuan. Pembagian kelompok dilakukan dengan cara cluster, yaitu dengan mengacak kelas yang ada di SMA X di Kota sehingga diperoleh 3 kelas, yaitu kelas X.4 (KK), kelas X.8 (KE FITD), dan X.9 (KE DITF). Begitupula untuk SMA Y di Desa yang dirandom secara Cluster, sehingga diperoleh 3 kelas, yaitu kelas X.8 (KK), kelas XI.IA.5 (KE FITD), dan XI.IA.A (KE DITF). KE adalah kelompok yang diberikan perlakuan berupa teknik DITF dan FITD. KK adalah kelompok yang tidak mendapat perlakuan apapun.

Randomisasi dilakukan sebagai bentuk kontrol terhadap penelitian agar sebelum perlakuan diberikan, variabel lain yang dapat memengaruhi penelitian dapat dikontrol, sehingga hasil yang diperoleh benar-benar pengaruh dari pemberian teknik DITF dan FITD terhadap perilaku prososial.

KE diberikan perlakuan berupa pernyataan teknik DITF dan FITD kemudian dibandingkan hasil dari subjek yang terpengaruh oleh teknik untuk memberikan bantuan. Untuk melihat peran intensi perilaku prososial maka diberikan skala perilaku prososial, sedangkan kelompok kontrol tidak diberikan perlakuan, dan langsung diberi skala perilaku prososial setelah diberikan pernyataan tujuan. Pernyataan teknik DITF dan FITD yang disusun telah dilakukan validasi oleh 
ahli dan dilakukan uji coba (Pilot study). Uji coba dilakukan pada SMA A dan B untuk menentukan urutan pernyataan yang tinggi, sedang, dan rendah. Pengujian pernyataan membantu peneliti untuk menentukan program yang sesuai dengan teknik yang akan diberikan.

Hasil uji coba mengenai jenis program yang sesuai dengan pernyataan DITF dan FITD terhadap 22 siswa SMA A dan SMA B menunjukkan bahwa, 10 dari 22 siswa (45,45\%) menyetujui program membantu teman sebaya yang kurang mampu sebagai program yang lebih diutamakan dari empat program yang diajukan yaitu membantu anak jalanan, membantu anak yatim, membantu bencana alam, dan membantu manusia lanjut usia. Hasil uji coba untuk menentukan urutan pernyataan yang tinggi, sedang, dan rendah yang dilakukan oleh 22 siswa SMA A dan B menunjukkan bahwa siswa yang menyatakan menyumbang Rp150.000 per bulan berada pada permintaan yang berat, lalu mengumpulkan buku dan pakaian berada pada urutan rendah, sedangkan menabung Rp1.000 per hari berada pada urutan sedang.

Teknik DITF adalah suatu strategi yang digunakan untuk memperoleh persetujuan dari individu lain dengan cara memberikan pernyataan yang setingkat lebih tinggi dari hal yang sebenarnya (hal yang diinginkan). Apabila permintaan tersebut ditolak maka segera ajukan permintaan kedua dengan tingkat yang lebih rendah dan masuk akal. Tingkat perilaku prososial yang ditinjau dari pemberian teknik DITF dapat dilihat dari perbandingan skor skala perilaku prososial antara KE dan KK. Pernyataan teknik DITF yang diberikan yaitu: (1) menjadi orang tua asuh bagi teman yang kurang mampu (siswa yang termarjinalkan) dalam hal material untuk melanjutkan sekolah dengan memberikan donasi sebesar Rp150.000/bulan; (2) menyumbangkan seragam, buku, atau barang lain yang sudah tidak digunakan oleh subjek tetapi masih dapat dimanfaatkan oleh teman yang kurang mampu dalam hal materi.

Teknik FITD merupakan salah satu cara untuk membuat individu tunduk dengan mengajukan permintaan yang lebih kecil. Setelah per- mintaan kecil tersebut terpenuhi, individu maka segera diberikan pernyatan selanjutnya yang lebih besar dan memang sudah direncanakan sejak awal. Tingkat perilaku prososial yang ditinjau dari pemberian teknik FITD dapat dilihat dari perbandingan skor skala perilaku prososial antara KE dan KK. Pernyataan teknik FITD yang diberikan yaitu: (1) mengisi angket mengenai pemberian perilaku prososial dalam sebuah program peduli kesejahteraan masyarakat; (2) menyumbangkan seragam, buku, atau barang lain yang sudah tidak digunakan oleh subjek tetapi masih dapat dimanfaatkan oleh teman yang kurang mampu dalam hal materi.

Pemilihan subjek dengan cluster sample. Jumlah subjek yang akan berpartisipasi dalam penelitian adalah161 siswa, 76 dari SMA X dan 85 dari SMA Y. Penempatan kelas yang diguna-kan dalam penelitian dilakukan dengan cluster sample. Metode yang digunakan adalah randomized experimental, dengan desain multiple treatments and controls with pretest. Untuk KE pertama diberikan perlakuan yaitu teknik DITF. Tester memberikan pernyataan yang berat, kemudian setelah ditolak maka tester akan melanjutkan instruksi untuk memberikan penawaran yang lebih rendah (pernyataan yang menjadi tujuan sebenarnya). Untuk KE kedua diberikan perlakuan yaitu teknik FITD. Tester memberikan pernyataan yang rendah, kemudian setelah disetujui maka tester akan melanjutkan instruksi untuk memberikan penawaran yang lebih tinggi (pernyataan yang menjadi tujuan sebenarnya). Untuk $\mathrm{KK}$, tester langsung memberikan pernyataan tujuan.

Pemberian pre-test dilakukan dengan jarak tiga hari sebelum perlakuan. Pemberian post-test dilakukan dengan jarak tiga hari setelah perlakuan. Pemberian follow-up dilakukan dengan jarak tiga hari setelah pemberian posttest. Skor yang digunakan dalam analisa data adalah total skor dari item pernyataan pada skala prososial. Untuk ketiga kelompok kemudian diberikan skala pengukuran perilaku prososial. Untuk lebih jelasnya, tahapan penelitian dapat dilihat pada gambar 2 .

Tabel 1

Partisipan penelitian

\begin{tabular}{cccc}
\hline Kelompok Penelitian & SMA X & SMA Y & Jumlah \\
\hline KK & (Kelas X.4) 25 & (Kelas X.8) 31 & 56 \\
KE DITF & (Kelas X.9) 22 & (Kelas XI IA.4) 24 & 46 \\
KE FITD & (Kelas X.8) 29 & (Kelas XI IA 5) 30 & 59 \\
\hline
\end{tabular}




\section{Gambar 1}

Desain penelitian

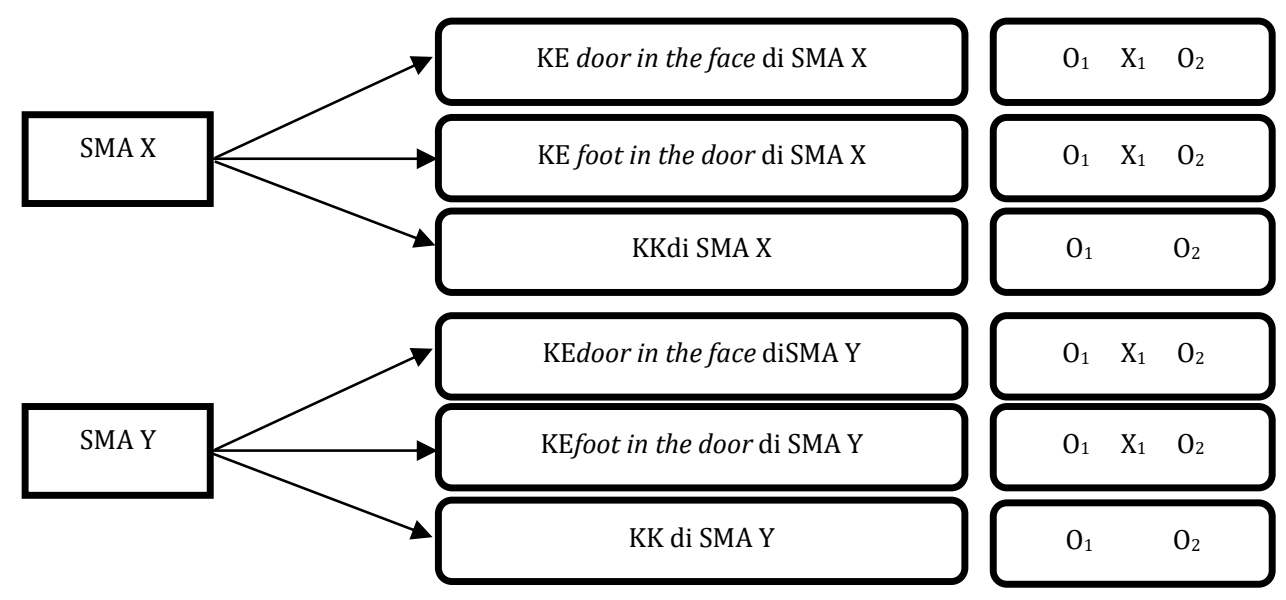

\section{Gambar 2}

Tahapan penelitian

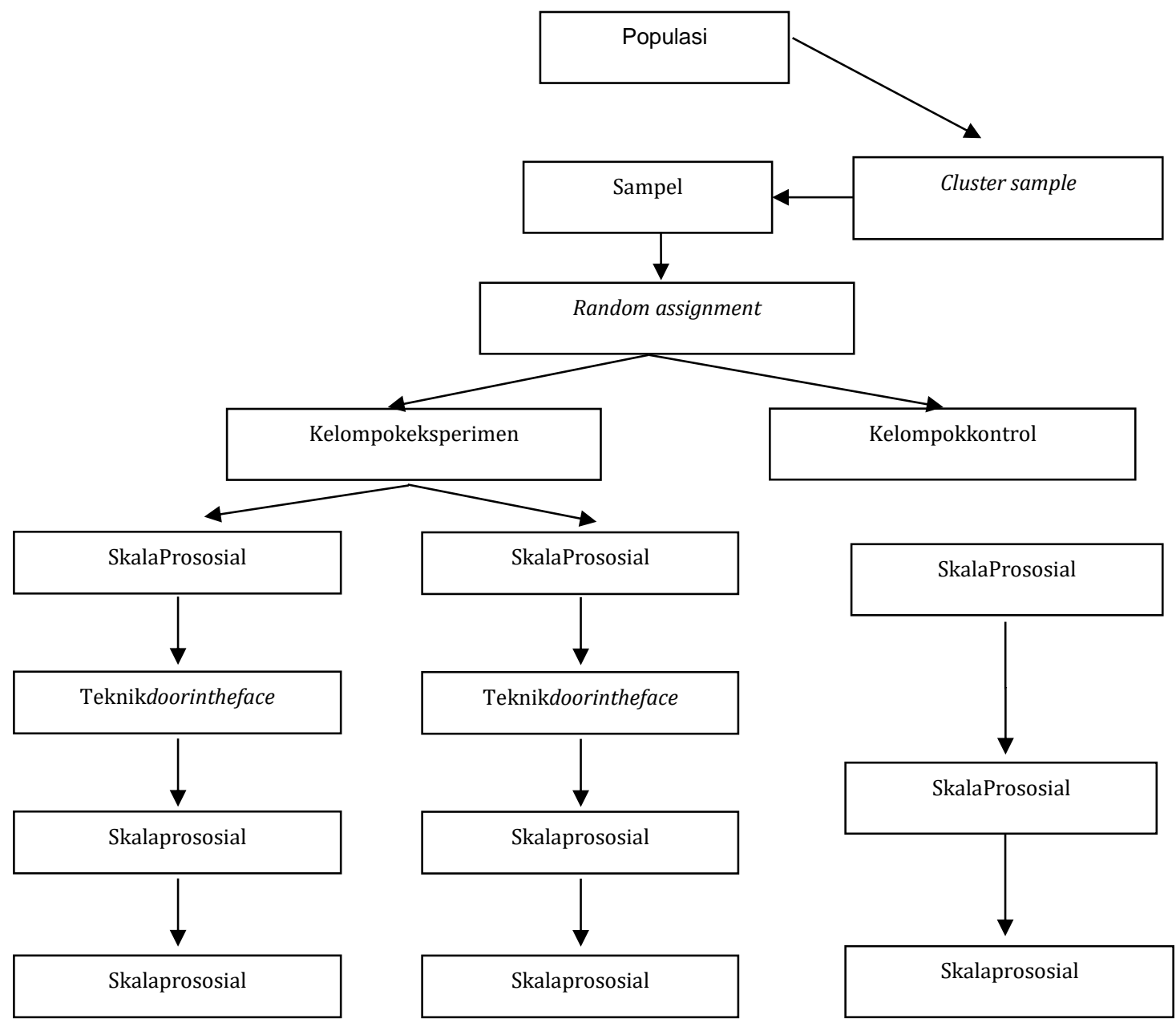




\section{Alat Ukur}

Instrumen penelitian menggunakan skala prososial model likert (0-4) yang terdiri atas 42 item yang mengacu pada enam aspek perilaku prososial yang dikemukakan oleh Mussen, dkk. (Cholidah, Ancok, \& Haryanto, 1996), yaitu kerja sama, membagi perasaan, menolong, kejujuran, memertimbangkan hak dan kesejahteraan indivi$\mathrm{du}$, serta berderma. Contoh item yang digunakan adalah "saya berpartisipasi dalam kerja bakti di lingkungan sekitar rumah", "saya mengacuhkan korban kecelakaan di jalan karena sudah banyak orang yang menolong", "saya menyumbangkan pakaian seragam sekolah yang sudah tidak terpakai", "saya menjadi relawan untuk acara sosial".

Skala prososial memiliki reliabilitas sebesar 0,885 cronbach alpha yang tergolong dalam kategori reliabilitas yang tinggi. Skala prososial diberikan sebelum dan setelah pemberian teknik DITF dan FITD. Instrumen ini digunakan untuk mengetahui perubahan intensitas perilaku prososial sebelum pemberian perlakuan, setelah pemberian perlakuan, dan follow-up. Skor dari skala perilaku prososial KE dan KK kemudian dibandingkan untuk melihat peran dari nilai prososial terhadap keberhasilan teknik DITF dan FITD.

\section{Teknik Analisis}

Pengujian terhadap hipotesis untuk melihat efektivitas pemberian teknik DITF dan FITD dalam meningkatkan perilaku prososial, meng-gunakan teknik analisis mixed-design anova de-ngan bantuan IBM SPSS Statistics 21 dengan menggunakan data pretest, posttest, dan follow-up.

\section{Hasil Penelitian}

Hasil analisis mixed-design anova melalui tiga tahap yaitu mauchly test of sphericity, tests of within subject effects, dan pairwise comparisons (Widhiarso, 2011). Berikut dipaparkan tiga temuan, perbedaan perilaku prososial seluruh partisipan penelitian (SMA X dan Y), perbedaan perilaku prososial partisipan SMA X, dan perbedaan partisipan SMA Y.

Berdasarkan hasil uji mixed design anova, pada tahap mauchly test of sphericity diperoleh nilai sign. $0,000<0,05$, signifikan, maka analisis dilanjutkan pada tahap tests of within subject effects dengan melihat baris greenhousegeisser. Hasilnya adalah $\mathrm{F}=4.805$, nilai sign. 0,003 $<0,05$ yang berarti bahwa terdapat interaksi antara time (pre-test, post-test, follow-up) dengan group (KE, KK). Interaksi menunjukkan bahwa perubahan skor pre-test menuju post-test dan follow-up pada kelompok KE dan KK adalah berbeda secara signifikan. Oleh karena itu, analisis dapat dilanjutkan pada tahap pairwise comparisons.

Berdasarkan hasil analisis pada tahap pairwise comparisons, diketahui bahwa perubahan perilaku prososial pada KE DITF adalah tidak signifikan ( $M D=-2.209 ; p=0.136>0.05)$, perubahan perilaku prososial pada KE FITD adalah signifikan (MD=-7390; $p=0.000<0.05)$, dan perubahan perilaku prososial pada $\mathrm{KK}$ adalah tidak signifikan (MD=-1.054; $\mathrm{p}=0.416>0.05)$. Hal ini menunjukkan bahwa pemberian teknik FITD efektif dalam meningkatkan perilaku prososial partisipan secara keseluruhan sedangkan teknik DITF tidak efektif dalam meningkatkan perilaku prososial partisipan secara keseluruhan. Hasil effect size menunjukkan nilai 0,058 yang berarti bahwa $5,8 \%$ perilaku prososial seluruh partisi-pan penelitian dipengaruhi oleh teknik DITF dan FITD dan selebihnya dipengaruhi oleh faktor lain.

Berdasarkan hasil uji mixed design anova, pada tahap mauchly test of sphericity diperoleh nilai sign. $0,000<0,05$, signifikan, maka analisis dilanjutkan pada tahap tests of within subject effects dengan melihat baris greenhouse-geisser. Hasilnya adalah $\mathrm{F}=2.561$, nilai sign. 0,041 <0,05 yang berarti bahwa terdapat interaksi antara time (pretest, posttest, follow-up) dengan group (KE, KK). Interaksi menunjukkan bahwa perubahan skor pre-test menuju post-test dan follow-up pada kelompok KE dan KK adalah berbeda secara signifikan. Oleh karena itu, analisis dapat dilanjutkan pada tahap pairwise comparisons.

Berdasarkan hasil analisis pada tahap pairwise comparisons, diketahui bahwa perubahan perilaku prososial pada KE DITF SMA X adalah tidak signifikan (MD=-0.818; $\mathrm{p}=0.594>0.05$ ), perubahan perilaku prososial pada KE FITD SMA $\mathrm{X}$ adalah signifikan (MD=-6.621; $\mathrm{p}=0.000<0.05$ ), dan perubahan perilaku prososial pada KK adalah tidak signifikan (MD=-0.880; $\mathrm{p}=0.541>0.05)$.

Hal ini menunjukkan bahwa pemberian teknik FITD efektif dalam meningkatkan perilaku prososial partisipan pada SMA X sedangkan teknik DITF tidak efektif dalam meningkatkan perilaku prososial partisipan pada SMA X. Hasil effect size menunjukkan nilai 0,066 yang berarti bahwa $6,6 \%$ perilaku prososial partisipan pada SMA X dipengaruhi oleh teknik DITF dan FITD dan selebihnya dipengaruhi oleh faktor lain.

Berdasarkan hasil uji mixed design anova, pada tahap mauchly test of sphericity diperoleh nilai sign. 0,000<0,05, signifikan, maka analisis dilanjutkan pada tahap tests of within subjects effects dengan melihat baris greenhouse-geisser. Hasilnya adalah $\mathrm{F}=2.448$, nilai sign. 0,048 $<0,05$ yang berarti bahwa terdapat interaksi antara 
time (pre-test, post-test, follow-up) dengan group (KE, KK). Interaksi menunjukkan bahwa perubahan skor pretest menuju post-test dan followup pada kelompok KE dan KK adalah berbeda secara signifikan. Oleh karena itu, analisis dapat dilanjutkan pada tahap pairwise comparisons.

Berdasarkan hasil analisis pada tahap pairwise comparisons, diketahui bahwa perubahan perilaku prososial pada KE DITF SMA Y adalah tidak signifikan (MD=-3.667; $\mathrm{p}=0.149>0.05$ ), perubahan perilaku prososial pada KE FITD SMA $\mathrm{X}$ adalah signifikan (MD=-7.903; $\mathrm{p}=0.000<0.05)$, dan perubahan perilaku prososial pada KK adalah tidak signifikan (MD=-1.194; $\mathrm{p}=0.566>0.05$ ). Hal ini menunjukkan bahwa pemberian teknik FITD efektif dalam meningkatkan perilaku prososial partisipan pada SMA Y sedangkan teknik DITF tidak efektif dalam meningkatkan perilaku prososial partisipan pada SMA Y. Hasil effect size menunjukkan nilai 0,058 yang berarti bahwa 5,8\% perilaku prososial partisipan pada SMA Y dipengaruhi oleh teknik DITF dan FITD dan selebihnya dipengaruhi oleh faktor lain.

\section{Gambar 3}

Skor rata-rata perilaku prososial seluruh partisipan

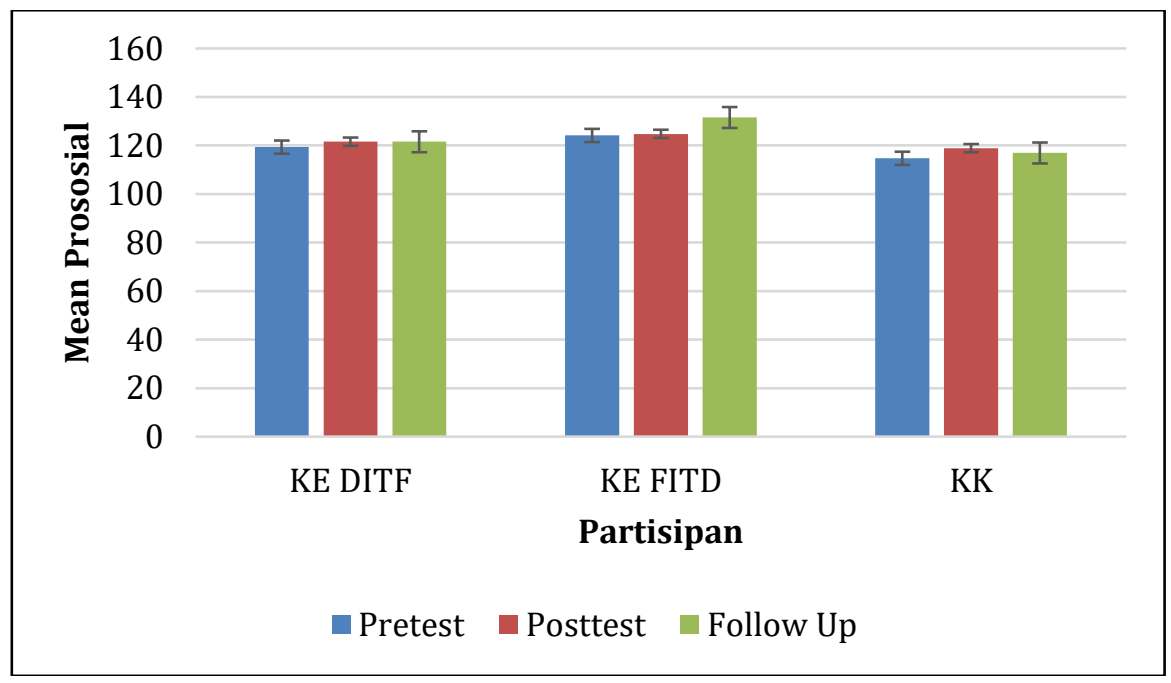

\section{Gambar 4}

Skor rata-rata perilaku prososial partisipan SMAX

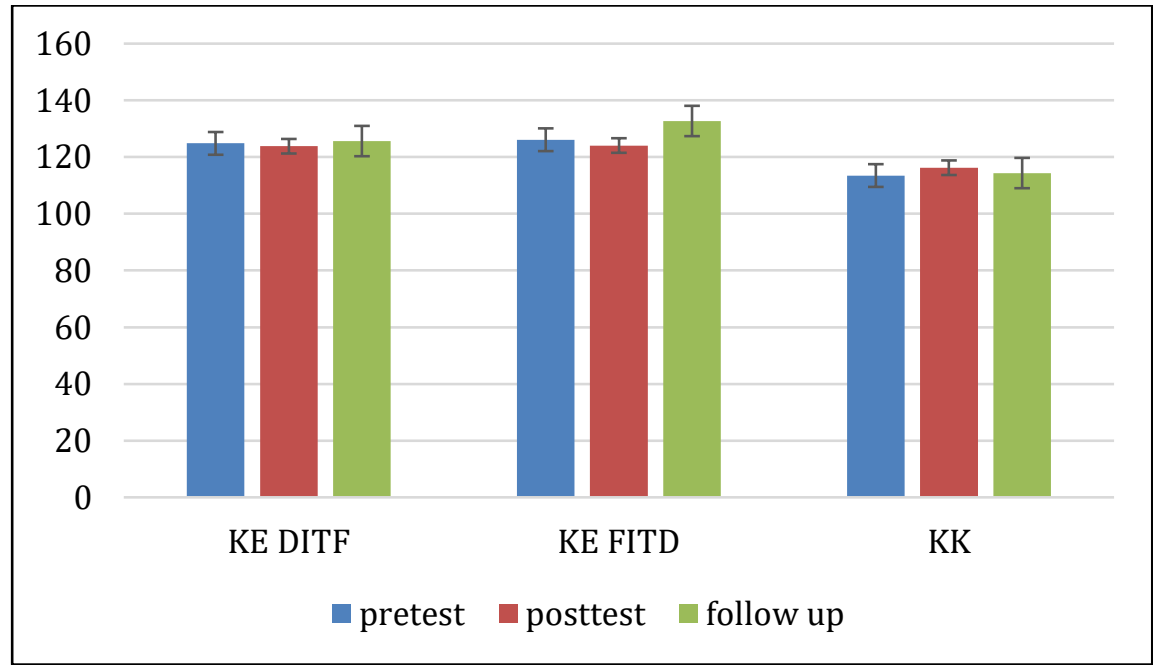


Gambar 5.

Skor rata-rata perilaku prososial partisipan SMA Y

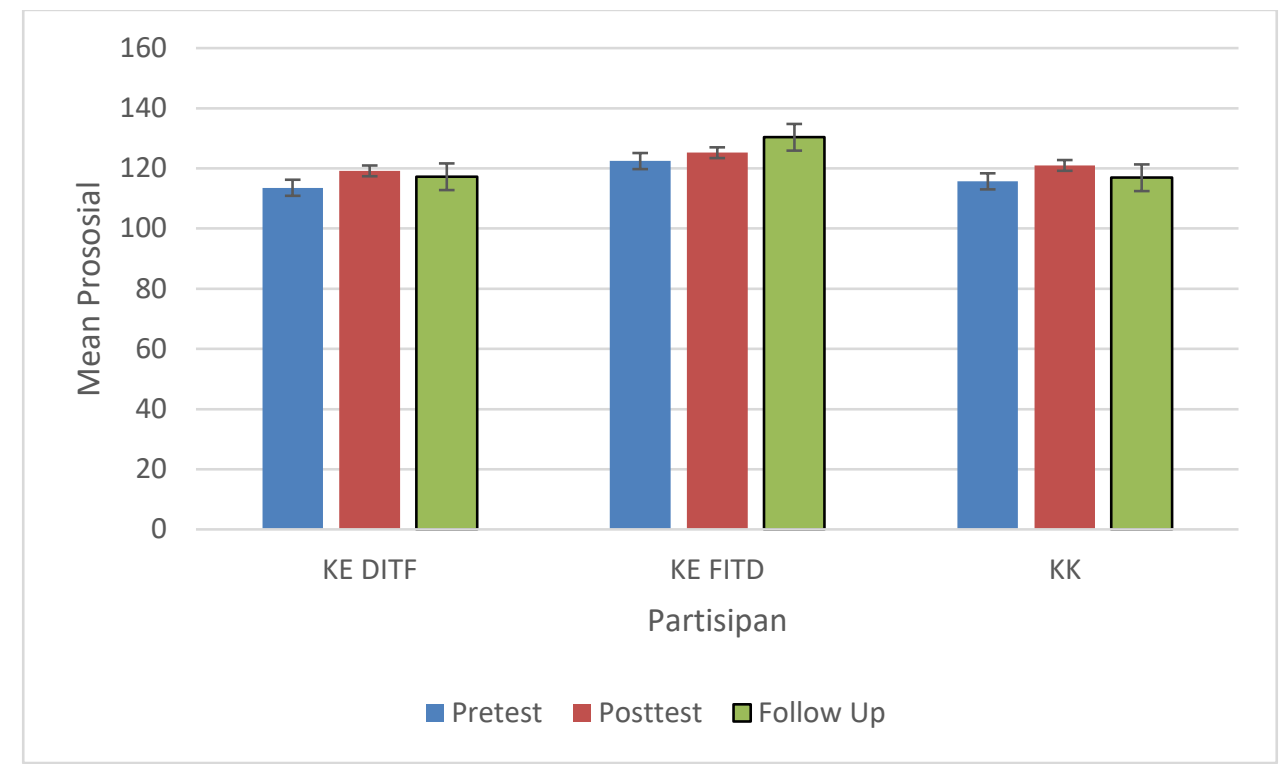

Tabel 2

Analisis efektivitas teknik ditf dan fitd terhadap perilaku prososial

\begin{tabular}{|c|c|c|c|c|c|c|c|c|}
\hline \multirow{3}{*}{ Sekolah } & \multicolumn{8}{|c|}{ Teknik } \\
\hline & \multicolumn{3}{|c|}{ DITF } & \multicolumn{3}{|c|}{ FITD } & \multicolumn{2}{|c|}{$\mathrm{K}$} \\
\hline & $\mathrm{n}$ & +1 & $-1,+2$ & $\mathrm{n}$ & -2 & $+1,+2$ & $\mathrm{n}$ & 1,2 \\
\hline SMA X & 22 & $\begin{array}{c}8 \\
(36,35 \%)\end{array}$ & $\begin{array}{c}14 \\
(63,63 \%)\end{array}$ & 29 & $\begin{array}{c}12 \\
(41,37 \%)\end{array}$ & $\begin{array}{c}17 \\
(58,62 \%)\end{array}$ & 25 & $\begin{array}{c}17 \\
(68 \%)\end{array}$ \\
\hline SMA Y & 24 & $\begin{array}{c}0 \\
0 \% \\
\end{array}$ & $\begin{array}{c}24 \\
(100 \%) \\
\end{array}$ & 30 & $\begin{array}{c}4 \\
(13,33 \%) \\
\end{array}$ & $\begin{array}{c}26 \\
(86,66 \%)\end{array}$ & 31 & $\begin{array}{c}16 \\
(51,61 \%)\end{array}$ \\
\hline Jumlah & 46 & $\begin{array}{c}8 \\
(17,39 \%)\end{array}$ & $\begin{array}{c}38 \\
(82,60 \%)\end{array}$ & 59 & $\begin{array}{c}16 \\
(27,11 \%)\end{array}$ & $\begin{array}{c}43 \\
(72,88 \%)\end{array}$ & 56 & $\begin{array}{c}33 \\
(58,92 \%)\end{array}$ \\
\hline
\end{tabular}

Berdasarkan tabel 2 diketahui bahwa pada KE DITF, sebesar $17,39 \%$ partisipan menyetujui penawaran pertama (menjadi orang tua asuh bagi teman yang kurang mampu dalam hal material untuk melanjutkan sekolah dengan memberikan donasi sebesar Rp150.000/bulan) hingga tidak dilanjutkan pada penawaran kedua, dan sebesar $82,60 \%$ partisipan menerima penawaran kedua setelah sebelumnya menolak penawaran pertama. Hal ini berarti bahwa dengan teknik DITF, sebesar 82,60\% partisipan menyetujui untuk memberikan bantuan (prososial) yang menjadi target agar partisipan menyetujui penawaran berupa menyumbangkan seragam, buku, atau barang lain yang sudah tidak digunakan oleh subjek tetapi masih dapat dimanfaatkan oleh teman yang kurang mampu dalam hal materi.

Pada KE FITD, sebesar 27,11\% partisipan menyetujui penawaran pertama (mengisi angket mengenai pemberian perilaku prososial dalam sebuah program peduli kesejahteraan masyarakat) namun melakukan penolakan pada penawaran kedua, dan sebesar $72,88 \%$ partisipan menerima penawaran kedua setelah sebelumnya menerima penawaran pertama. Hal ini berarti bahwa dengan teknik FITD, sebesar $72,88 \%$ partisipan menyetujui untuk memberikan bantuan (prososial) yang menjadi target agar partisipan menyetujui penawaran berupa menyumbangkan seragam, buku, atau barang lain yang sudah tidak digunakan oleh subjek tetapi masih dapat dimanfaatkan oleh teman yang kurang mampu dalam hal materi.

Pada KK, sebesar 58,92\% partisipan menerima penawaran tanpa penerapan teknik DITF dan FITD. Hal ini berarti bahwa tanpa penerapan DITF maupun FITD, sebesar 58,92\% partisipan menyetujui untuk memberikan bantuan (prososial) berupa menyumbangkan sera- 
gam, buku, atau barang lain yang sudah tidak digunakan oleh subjek tetapi masih dapat dimanfaatkan oleh teman yang kurang mampu dalam hal materi.

\section{Diskusi}

Berdasarkan hasil analisis data diketahui bahwa ada perbedaan efektivitas pemberian teknik DITF dan FITD dalam meningkatkan perilaku prososial yang berarti bahwa hipotesis pertama penelitian ini diterima. Teknik FITD lebih efektif dalam meningkatkan perilaku prososial dibandingkan teknik DITF. Psikolog sosial telah mempelajari mengenai perbandingan efektivitas teknik DITF dan FITD dalam berbagai kajian. Dillar (Rodafinos, Vucevic, \& Sideridis, 2005) mengemukakan bahwa ketika dibandingkan secara terpisah dengan kelompok kontrol kedua teknik tersebut meningkatkan kepatuhan dari 15\% sampai $25 \%$, namun ketika dibandingkan secara langsung hasilnya menjadi samar-samar. Hasil yang diperoleh dalam penelitian ini menunjukkan bahwa terdapat perbedaan yang signifikan antara teknik DITF dan FITD dalam meningkatkan perilaku prososial. Teknik FITD lebih efektif terhadap pembentukan prososial ditinjau dari pemberian skala prososial.

Hasil penelitian yang dilakukan oleh Henderson dan Burgoon (2013) menunjukkan bahwa teknik DITF dalam hal-hal yang sifatnya abstrak mengurangi kepatuhan partisipan dalam menunjukkan perilaku prososial. Sesuai dengan prinsip kerja DITF, partisipan diberikan penawaran yang lebih tinggi terlebih dahulu yaitu untuk menjadi orang tua asuh bagi teman yang kurang mampu dalam hal material untuk melanjutkan sekolah dengan memberikan donasi sebesar Rp150.000/bulan. Pada penelitian ini, $82,60 \%$ siswa melakukan penolakan hingga diajukan penawaran selanjutnya yaitu menyumbangkan seragam, buku atau barang berharga lainnya yang masih layak pakai. Hal ini berbeda dengan teknik FITD, individu cenderung mempertahankan citra diri sebagai orang yang prososial ketika menyanggupi permintaan awal. Sesuai dengan prinsip kerja FITD, partisipan diberikan penawaran yang rendah kemudian meningkat ke penawaran yang lebih tinggi seperti pada penelitian ini, pada awalnya partisipan hanya diminta untuk mengisi angket mengenai pemberian perilaku prososial dalam sebuah program peduli kesejahteraan masyarakat. Ada $72,88 \%$ partisipan menyetujui penawaran ini hingga diajukan penawaran kedua yang lebih tinggi yaitu menyumbangkan seragam, buku barang lain yang masih layak pakai. Partisipan yang telah menyetujui penawaran pertama, juga menunjukkan persetujuan terhadap penawaran kedua. Hal inilah yang dimaksud dengan individu mempertahankan citra diri sebagai orang yang prososial ketika menyanggupi permintaan awal.

Burger (Taylor, Peplau, \& Sears, 2009) mengemukakan bahwa proses psikologis dapat digunakan menjelaskan mengenai teknik FITD, yaitu didasarkan pada teori persepsi diri. Teori tersebut menjabarkan bahwa citra diri berubah sebagai akibat dari ketundukan awal. Individu yang telah setuju pada permintaan awal yang memang sulit untuk ditolak akan mengubah persepsi dirinya, sehingga ketika permintaan kedua diberikan maka individu tidak akan menolak dan memberikan reaksi patuh pada permintaan tersebut.

Lebih lanjut Taylor, Peplau, dan Sears (2009) mengemukakan bahwa keinginan untuk menganggap diri sendiri sebagai individu yang bertindak konsisten ikut berperan dalam teknik FITD. Cialdini (2007) mengemukakan bahwa konsistensi dapat menjadi suatu yang sangat kuat dalam melandasi perilaku individu. Konsisten adalah suatu sikap yang dihargai dan diakui dalam banyak situasi dan ketidakkonsistenan biasanya dianggap sebagai suatu karakter personal yang buruk. Konsisten yang tinggi sering kali diasosiasikan dengan kekuatan personal dan intelektual.

Pemberian teknik DITF dan FITD lebih efektif dalam meningkatkan perilaku prososial di SMA Y dibandingkan di SMA X yang berarti bahwa hipotesis kedua penelitian ini diterima. Hasil dari pengujian tersebut memperlihatkan adanya pengaruh demografi (tempat tinggal kota dan desa) terhadap efektivitas teknik DITF dan FITD dalam meningkatkan perilaku prososial. Hal tersebut sesuai dengan penelitian yang dilakukan ole La Vane (Sarwono, 1999) di 36 kota di Amerika Serikat. Hasilnya menunjukkan bahwa semakin besar kota maka semakin jarang individu melakukan perilaku menolong, sementara semakin kecil kota maka semakin banyak yang menolong. La Vane menjelaskan gejala tersebut sebagai kejenuhan mental (compattion fatigue atau sensory overload) yang lebih banyak dialami penduduk kota besar dibandingkan penduduk kota kecil. Mungkin terjadi bahwa pola perilaku prososial di desa dan di kota berbeda secara signifikan sehingga intervensi yang sama menghasilkan hasil berbeda.

Gueguen, Martin, Silone, dan David (2016) menambahkan bahwa teknik FITD cukup dipengaruhi oleh faktor budaya yang ada di lingkungan sekitar sehingga antar masyarakat dapat memiliki perilaku prososial, juga dipengaruhi oleh faktor budaya. Terdapat kelompok masyarakat dengan budaya kebersamaannya tinggi dan juga kelompok masyarakat dengan tingkat individualitas yang sangat tinggi. Hal ini cukup 
berpengaruh terhadap keputusan masyarakat dalam menyatakan akan menolong atau tidak.

Akbar dan Listiara (2012) mengemukakan bahwa prososial sebagai bentuk kepedulian sosial terhadap lingkungan semakin berkurang ketika mobilitas tinggi khususnya di kota-kota besar, setiap individu menjadi semakin sibuk dan terpaku pada kepentingan pribadi masingmasing. Hal tersebut sejalan dengan efektivitas teknik DITF dan FITD dalam meningkatkan perilaku prososial di SMA X yang notabenenya berada di Kota sedangkan SMA Y berada di Desa. Teknik DITF dan FITD dalam meningkatkan terhadap perilaku prososial lebih efektif dilakukan di kota atau desa yang mobilitas penduduknya masih rendah. Kedua teknik ini memiliki implikasi untuk mendapatkan kesepakatan dalam kesanggupan memberikan pertolongan/perilaku prososial. Hal tersebut mendukung penelitian sebelumnya yang dilakukan oleh Barr dan HigginsD'Alessandro (2007) bahwa empati dan perilaku prososial siswa SMA berkorelasi dengan konteks budaya di sekolah.

\section{Kesimpulan}

Berdasarkan hasil penelitian, dapat disimpulkan bahwa: 1) ada perbedaan efektivitas pemberian teknik DITF dan FITD dalam meningkatkan perilaku prososial. Teknik FITD lebih efektif dalam meningkatkan perilaku prososial dibandingkan teknik DITF; 2) Ada perbedaan keefektifan pemberian teknik kesepakatan (DITF dan FITD) dalam meningkatkan perilaku prososial di SMA X (Kota) dan SMA Y (Desa). Pemberian teknik DITF dan FITD lebih efektif dalam meningkatkan perilaku prososial di SMA Y dibandingkan SMA X.

\section{Keterbatasan dan saran.}

Hasil penelitian ini memiliki keterbatasan dalam: (1) menjelaskan dinamika psikologis partisipan dalam melakukan tindakan prososial, mengingat partisipan penelitian merupakan siswa SMA yang masih berada dalam tanggungan orang tua; (2) penelitian ini belum menjangkau alasan dibalik partisipan ingin berperilaku prososial dan partisipan yang tidak ingin berperilaku prososial; (3) penelitian-penelitian tentang teknik DITF dan FITD sangat terbatas dan belum ada penelitian-penelitian terbaru sehingga menyulitkan peneliti melakukan perbandingan secara mendalam terhadap penelitian-penelitian sebelumnya.

Oleh karena itu, disarankan kepada peneliti selanjutnya agar: (1) menggunakan partisipan yang telah memiliki penghasilan mandiri sehingga keputusan untuk menunjukkan perila$\mathrm{ku}$ prososial, sepenuhnya menjadi tanggung jawab partisipan; (2) menggunakan metode penelitian eksperimen dengan pendekatan kualitatif untuk mendalami dinamika psikologis partisipan yang menunjukkan perilaku prososial dan partisipan yang tidak menunjukkan perilaku prososial; (3) melakukan replikasi dan memperbanyak penelitian-penelitian mengenai teknik DITF dan FITD sehingga dapat menghasilkan teori-teori terbaru yang mengikuti perkembangan zaman.

\section{Daftar Pustaka}

Akbar, Z., \& Listiara, A. (2012). The Difference Between The Prosocial Tendency Regular Classes and Special Classes at SMAN 1 And SMAN 3 Semarang. Empati, 1(1), 120-138. Retrieved from https://ejournal3.undip.ac.id/index.php/ empati/article/view/438.

Baron, R. A., \& Byrne, D. (2005). Psikologi sosial. Jilid 2. (R. Djuwita, Penerjemah). Jakarta: Erlangga.

Barr, J., \& Higgins-D’Alessandro, A. (2007). Adolescent empathy and prosocial behavior in the multidimensional context of school culture. The Journal of Genetic Psychology, 168(3), 231-250. https://doi.org/10.3200/gntp.168.3.231250.

Burger, J. M. (1999). The foot-in-the-door compliance procedure: A multiple-process analysis and review. Personality and Social Psychology Review, 3(4), 303-325. https://doi.org/10.1207/s15327957pspr 0304_2

Cann, A., Sherman, S. J., \& Elkes, R. (1975). Effects of initial request size and timing of a second request on compliance: The foot in the door and the door in the face. Journal of Personality and Social Psychology, 32(5), 774-782. https://doi.org/10.1037/00223514.32.5.774.

Caprara, G. V., Kanacri, B. P. L., Gerbino, M., Zuffiano, A., Alessandri, G., Vecchio, G., Caprara, E., Pastorelli, C., \& Bridglall, B. (2014). Positive effects of promoting prosocial behavior in early adolescence: Evidence from a school-based intervention. International Journal of Behavioral Development, 38(4), 386-396. https://doi.org/10.1177/016502541453 1464.

Cheon, S. H., Reeve, J., \& Ntoumanis, N. (2018). A needs-supportive intervention to help PE teachers enhance students' prosocial behavior and diminish antisocial behavior. Psychology of Sport \& Exercise, 35, 74-88. 
https://doi.org/10.1016/j.psychsport.20 17.11.010.

Cialdini, R. B., Vincent, J. E., Lewis, S. K., Catalan, J., Wheeler, D., \& Darby, B. L. (1975). Reciprocal concenssions procedur for inducing compliance: The door in the face technique. Journal of Personality and Social Psychology. 206-215. https://doi.org/10.1037/h0076284

Cialdini, R. B. (2007). Psikologi persuasif: Merekayasa kepatuhan. Tri Wibowo Budi Santoso, Penerjemah). Jakarta: Kencana.

Cholidah, L., Ancok, D., \& Haryanto. (1996). Hubungan kepadatan dan kesesakan dengan stres dan intensi prososial pada remaja di pemukiman padat. Jurnal Psikologika. 1(1), 56-64. https://doi.org/10.20885/psikologika.vol 1.iss1.art6.

Costin, S. E., \& Jones, D. C. (1992). Friendship as a facilitator of emotional responsiveness and prosocial interventions among young children. Developmental Psychology, 28(5), 941-947. https://doi.org/10.1037/00121649.28.5.941.

De Grave, J. M. (2017). Seperti apa bedanya keseharian anak SMA di kota dan desa?.Penelitian,

https://www.rappler.com/indonesia/ayo -indonesia/178092-keseharian-anaksma-yogyakarta.

Eastwick, P. W., \& Gardner, W. L. (2008). Is it a game? evidence for sosial influence in the virtual world. Journal of Sosial Influence, 4(1), 18-32. https://doi.org/10.1080/ 15534510802254087.

Faridah, D. N. (2011). Perbedaan tingkah laku altruisme antara remaja kota dengan pedesaan: Studi komparasi pada siswa SMAN I Sumedang dengan SMAN Tanjungkerta. Diploma Thesis. Bandung: UIN Sunan Gunung Djati.

Festinger, L. (1962). A theory of cognitive dissonance (Vol. 2). Stanford university press.

Flook, L., Goldberg, S. B., Pinger, L., \& Davidson, R. J. (2015). Promoting prosocial behavior and self-regulatory skills in preschool children through a mindfulness-based kindness curriculum. Developmental Psychology, $\quad$ 51(1), 44-51. https://doi.org/10.1037/a0038256.

Goodwin, C. J. (2010). Research in psychology methods and design $6^{\text {th }} E d$. America: John Wiley \& Sons, Inc.

Gueguen, N., Martin, A., Silone, F., \& David, M. (2016). Foot-in-the-door technique and reduction of driver's aggressiveness: A field study. Science, 36, 1-5. https://doi.org/10.1016/j.trf.2015.10.00 6.

Gueguen, N., Pascual, A., \& Dagot, A. (2002). LowBall and compliance to a request: An application in a field setting. Psychological Reports, $\quad$ 91(1), 81-84. https://doi.org/10.2466/pr0.2002.91.1.8 1.

Henderson, M. D., \& Burgoon, E. M. (2013). Why the-door-in-the-face technique can sometimes backfire: A construal-level account. Social Psychological and Science, 5(4), 475-483. https://doi.org/10.1177/194855061350 6719.

Millar, M. (2002). Effects of a guilt induction and guilt reduction on door in the face. Journal of Communication Research, 29(6), 666$680 . \quad$ https://doi.org/10.1177/ 009365002237831.

Mowen, J. C., \& Cialdini, R. B. (1980). On implementing the door-in-the-face compliance technique in a business context. Journal of Marketing Research, 17(2), 253-258. https://doi.org/10.1177/2F0022243780 01700210

Nashori, F. (2008). Psikologi sosial islami. Bandung: Refika Aditama.

O'keefe, D. J., \& Figge, M. (1997). A guilt-based explanation of the door-in-the-face influence strategy. Human Communication Research, 24(1), 64-81. https://doi.org/10.1111/j.14682958.1997.tb00587.x

Pliner, P., Hart, H., Kohl, J., \& Saari, D. (1974). Compliance without pressure: Some further data on the foot-in-the-door technique. Journal of Experimental Social Psychology, 10(1), 17-22. https://doi.org/10.1016/00221031(74)90053-5

Rodafinos, A., Vucevic, A., \& Sideridis, G. D. (2005). The effectiveness of compliance techniques: Foot in the door versus door in the face. The Journal of Social Psychology. 145(2), 237-239. https://doi.org/10.3200/SOCP.145.2.237 $-240$

Sarwono, S. W. (1999). Psikologi sosial: Individu dan teori-teori psikologi sosial. Jakarta: Balai Pustaka.

Shadiqi, M. A. (2018). Perilaku Prososial. Dalam A. Pitaloka, Z. Abidin, \& M. N. Milla (Eds.), Buku psikologi sosial, pengantar teori dan penelitian (227-260). Jakarta: Salemba Humanika 
Taylor, S. E., Peplau, L. A., \& Sears, D. O. (2009). Psikologi sosial. (Wibowo. B. S., Penerjemah). Jakarta: Kencana.

Tusing, K. J., \& Dillard, J. P. (2000). The psychological reality of the door-in-theface: It's helping, not bargaining. Journal of Language and Social Psychology, 19(1), 525.

https://doi.org/10.1177/0261927X0001 9001001
Widhiarso, W. (2011). Aplikasi anava campuran untuk desain eksperimen pre-post test design. Artikel Statistik, http://widhiarso.staff.ugm.ac.id/files/Apl ikasi\%20Anava \%20Mixed\%20Design\%20untuk\%20Eks perimen-revised\%202011.pdf. 